\title{
Developing an Organizational Reference Model by Selecting and Integrating Multiple References
}

\author{
Thaís Spiegel \\ Production Engineering Program, Rio de Janeiro Federal University \\ PO Box 68.507, Rio de Janeiro, Brazil \\ Tel: 55-21-2562-7415Ｅ-mail: thais.spiegel@gpi.ufrj.br \\ Heitor Mansur Caulliraux \\ Production Engineering Program, Rio de Janeiro Federal University \\ PO Box 68.507, Rio de Janeiro, Brazil \\ Tel: 55-21-2562-7415Ｅ-mail: heitor.caulliraux@gpi.ufrj.br
}

\begin{abstract}
Received: November 4, 2011 Accepted: November 16, 2011 Published: January 1, 2012
doi:10.5296/jmr.v4i1.1059ＵRL: http://dx.doi.org/10.5296/jmr.v4i1.1059
\end{abstract}

\begin{abstract}
In view of the growing supply of reference models in various domains and in different formats, and the potential benefits to organizations using them, this article proposes to (1) present the theoretical background to the subject, and (2) situate and discuss issues associated with integrating such references. Adopting multiple reference models poses practical problems for organizations as regards where to look for the models, which to adopt, and once selected, how to ensure the references are consistent with each other and suited to the organization's particular features. As a possible avenue to solutions, this text describes the conception of an organization-specific reference model. The model proposed can be constructed by way of an articulated solution based on one or more reference models, which were selected thematically, subjected to adjustments for coherence and interrelationship, matched against the organizational culture, and explicitly formulated.
\end{abstract}

Keywords: Reference Model, Integration, Organizational Model 


\section{Introduction}

BURLTON (2010) notes that the last decade has witnessed the growth of a series of specific value chain frameworks and reference models that embody a set of best practices for viewing and managing the work of organizations. The purpose of these frameworks is to serve as a starter kit or point of comparison for organizations wanting some consistent means of evaluating themselves against a benchmark.

In addition, the needs of customer relations (LIMSARUN \& ANURIT, 2011), of meeting legal requirements, regulations, historical trajectory, and so on, have led to the adoption of references that legitimize - even if only partly - organizations' management capability in the business environment (WILKINSON \& DALE, 1999). In this respect, some authors argue that organizations should seek fit among the business environment, their strategies, and the main components of management: people, architecture, routines and culture (ROBERTS, 2005), as a way of achieving better performance or even surviving on the market (ASLAM \& SARWAR, 2010).

In the endeavor to orient their decisions, business managers and researchers use modeling constantly to help understand the organization's business and internal communication (SHEHABUDDEEN et al., 1999). In recent years, many organizations have implemented references to guide and improve how they are managed (BERNARDO et al., 2008). These models are "packages" (sets of structured concepts) of guidelines and/or solutions used by other organizations, and are being known in management as "reference models".

Normally organized as a hierarchy of functions, processes and activities, with or without interdependencies, they provide names, descriptions, indicators and other attributes that can be re-utilized. However, these frameworks are not always relevant to the specific nature of the business. They may also use terminologies that clash culturally. Few organizations can expect simply to take such references and apply them unthinkingly or without some evaluation and modification (BURLTON, 2010).

The fact that each model has a specific focus and poses particular needs makes them difficult to manage in isolation. Managers are realizing that managing these models without integrating them can cause a lot of problems (PAGLIUSO et al., 2010). For that reason, one of the present focuses of research in this field is how these reference models can be integrated (FONTES, 2010) for coordinated deployment of all the potential such tools have to offer.

In addition, MATOOK \& INDULSKA (2009) highlight the lack of methods for building reference models, pointing out that little literature is available and that most methods are directed to constructing information system reference models, which have particular characteristics not shared by other types.

Given this scenario in the literature, this paper proposes to systemize the theoretical framework associated with reference models, and endeavor to formulate the issues raised by what for organizations is a practical problem as to what models to adopt, and once selected, how to adopt them jointly in a manner suited to the particular features of each organization. 
In order to set out that content, the article is organized as follows, presenting: first, a brief review of the theory and main typologies used in this area, so as to summarize how the object is understood; second, the present scenario, with growing use of reference models, and an examination of the related problems; third, one possible approach for organizations to creating their own integrated reference model; fourth, a discussion of ways of selecting and integrating models, and the related benefits and limitations; and, last, some final remarks on issues raised by the adoption of multiple reference models.

\section{Theoretical frame of reference}

This section offers a brief review of the theory of the study object. It first examines what is understood by the terms "reference" and "model", and then discusses the ways the expression "reference model” is used. It characterizes the study object as understood in this article, summarizes why it is important, and presents some typologies.

\subsection{Reference models}

The various meanings of the word "model", as compiled by the dictionary, are associated with the idea of a representation of something that is intended to be reproduced; a formula that serves for arranging or ordering; or an image, form, or pattern to be imitated; and so on. According to PIDD (1999), a model can be understood as "an external and explicit representation of part of reality as seen by the people who wish to use that model to understand, to change, to manage, and to control that part of reality in some way or other”.

ANDERSON et al. (1991 in SHEHABUDDEEN et al., 1999) states that "Models are representations of real objects or situations. These representations, or models can be presented in various forms”. He categorizes models into three types: (1) models that do not have the same physical appearance as the object modeled, but are an analogy; (2) models that are physical replicas of real objects; and (3) models that represent problems by a system of symbols or mathematical representations. The first type defined by ANDERSON et al. (1991 in SHEHABUDDEEN et al., 1999) corresponds to models that offer an analogy to the theoretical proposal for organization management and, in this article, will be referred to as the “management reference model”.

There is a problem associated with the use of the term "reference model" (FETTKE \& LOOS, 2007). In research and in practice, different types of model are denominated "reference models" (THOMAS, 2005). The term “reference model” has become very popular in recent years, and has come to be surrounded by considerable confusion (FETTKE \& LOOS, 2007; ROSEMANN \& VAN DER AALST, 2007). It belongs to a class of terms that are widely used, but still not very clearly defined (HARS, 1994 apud THOMAS, 2005).

SHEHABUDDEEN et al. (1999) report that a broad literature review reveals that authors using this term do not define exactly what they consider to be a "reference model". The confusion starts with the word "reference" itself. THOMAS (2005) explains that etymologically the term "reference" has a double meaning: a recommendation, and the meaning of bearing a relation to something, quoting something or alluding to something. 
In his examination of some of the uses, THOMAS (2005) reports that the term "reference" was first used in $19^{\text {th }}$-century business language to designate a person or a firm capable of giving information as to the reliability of a business partner. It was not until later that it came to be mean a person or a place one could turn to for a (social) recommendation. In linguistics, "reference" also refers to the relationship between linguistic symbols and their contributor in the extra-linguistic world. In economics, "reference" is used to describe a state that cannot be attained in reality, or an exemplary state of affairs. Thus, for example, the perfect competition model - discarded largely for its restrictive assumptions - is accepted as a reference.

Returning to reference models, most citations on this term refer to information system reference models, which serve as a basis for firms to develop their software to support this area (SCHELP \& WINTER, 2006). In this field, an effort was made in the late 1990s to arrive at a more precise definition, during the Reference Modeling conference (conference information available at www.wi.uni-muenster.de/is/Tagung/). All the same, even in the Information Science domain, the general tendency to describe information models as reference models still persists in the literature (THOMAS, 2007). In this context, the statement by LEHNER (1995: 126 apud THOMAS, 2005) that "in a sense every model can be understood as a reference model" is not surprising. The question of why recommended models "warrant" the attribute "reference" continues unanswered in the literature.

However, in addition to information models, there is also a set of reference models that support organization management by offering orientation on how to improve it on the bases of analyses of the best practices found in the market. Most of those practices have arisen in leading firms or derived from solutions used by various firms (KELLER \& TEUFEL, 1998).

On the basis of a compilation of definitions by various authors (Vernadat, 1996; Shehabuddeen et al., 1999; Van der Aalst et al., 2005, Schelp \& Winter, 2006; Recker et al., 2007; Vom Brocke, 2007; Fettke \& Loss, 2007; Thomas, 2007; Rosemann \& Van Der Aalst, 2007), PAGLIUSO et al. (2010: 47) proposes that management reference models are "standardized, generic models that perform a reference role for decision makers as regards the practices to be employed in organizational operations and processes”.

These are considered "information bases" created so that the knowledge contained in them ca be reused by other organizations, with a view to facilitating the design of new practices (processes, organizational architectures, systems etc.) in the organization or even as a yardstick for reviewing existing ones and indicating possible changes. This is described in the literature as the "design by reuse” paradigm (VAN DER AALST et al. 2005), but as these models are created so that the information can be used (or reused) by one or more organizations.

Three strong points underscore the importance of reference models: (1) a solid reference model means gains of scale. Someone (generally a broad set of people) has worked on a large number of texts and summarized them into a reference model; (2) using the reference model increases the speed at which some academic and/or management processes are executed; and (3) partly deriving from the foregoing, there is the possibility of introducing complex subjects into organizations via reference models. One important example is the issue of innovation, 
which reference models can make more tangible, and easy to understand and apply.

\subsection{Types of reference model}

Reference models can display different characteristics: they can be made up of requirements or guidelines. Guidance reference models offer a series of recommendations on how to deal with aspects of organization management and, accordingly, can be identified as prescriptive. Requirement reference models, in turn, are made up of questions with respect to these various aspects of organization management, and can thus be identified as non-prescriptive.

SHÜTTE (1998 apud MENDLING et al., 2005) identify three types of reference models found in the literature by their application/use: (1) process reference models: these present the stages to be completed in order to achieve specific objectives more efficiently, and are often found in the fields of Software Engineering and Business Process Engineering (SCHELP \& WINTER, 2006); (2) Information Systems Reference Models are systems models whose purpose is to guide the development of specific solutions for a given organization. The main reference for this category in the literature is the SAP R/3 reference model, which is much used in organizations and other information systems; and (3) Organizational Reference Models describe the different aspects of subdivisions of a given type of organization, for example, bank management, manufacturing, public administration, retail etc. (SCHELP \& WINTER, 2006).

Another typology is proposed by BURLTON (2010), who distinguishes reference models into: (1) generic models, intended to describe organizations of all types in all sectors; (2) industry-specific models, that designate a set of existing and emerging models designed to describe an industry as a whole; (3) domain-specific models, developed around specific functions in an organization and the processes within them; and (4) process, lifecycle and value chain models.

As a way of organizing these multiple typologies, FETTKE et al. (2005) propose the structure shown in Figure 1, below. This is intended to lay a common foundation for cataloging existing reference models, but also performs the function of distinguishing and localizing the particular features of the various types of reference model. 


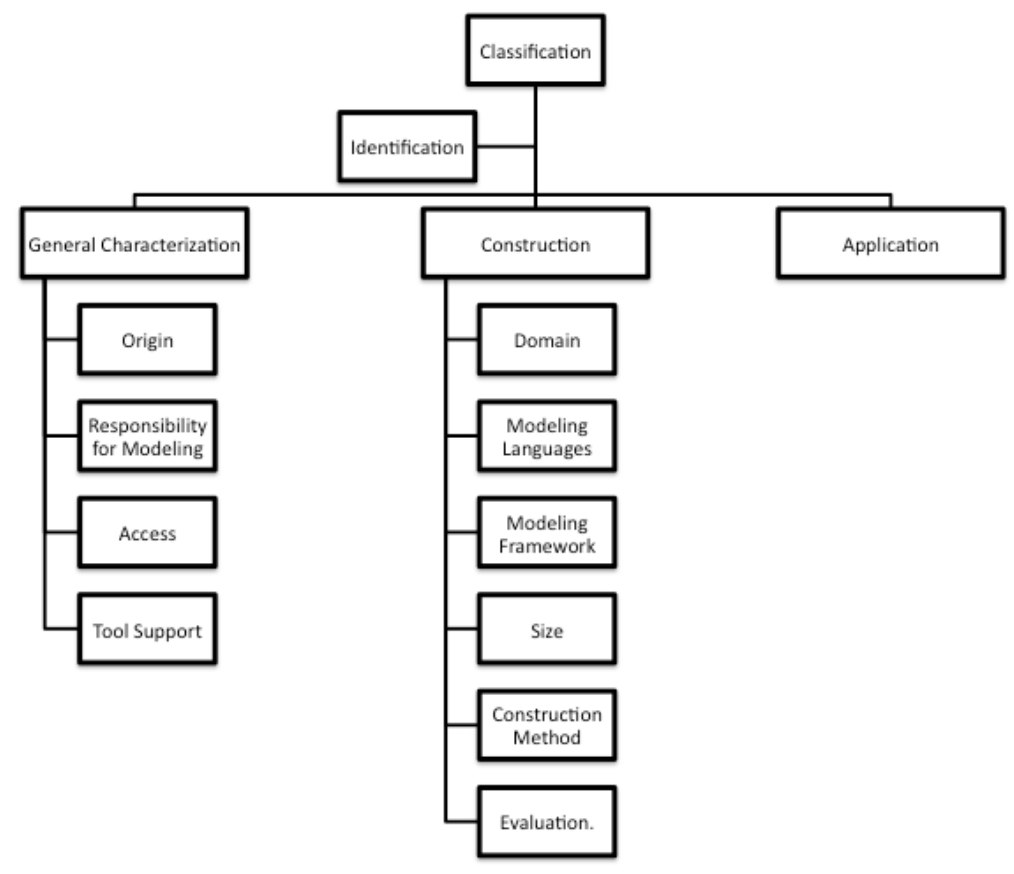

Figure 1. Classification of reference models. Source: FETTKE et al. (2005)

We will return to these typologies when discussing selection of reference models and analysis of consistency among models. The typologies will be examined in detail in those sections, but what can be said here is that, for example, it is easier to evaluate fit and consistency among the parts of references of the same type; and, on the other hand, requirements frameworks are the type of model that it is suggested should be used as a basis for integration, as the point of departure for the work of reconciling references for use in a particular organization.

\section{The problems of using multiple reference models}

Reference models became widespread in the late 1970s and in the 1980s, and were used and referred to on a large-scale by organizations for constructing their specific solutions, and in their commercial relations. Figure 2 shows a timeline for reference models in four key thematic areas. 


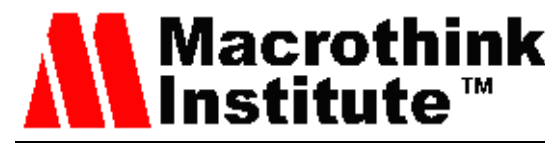

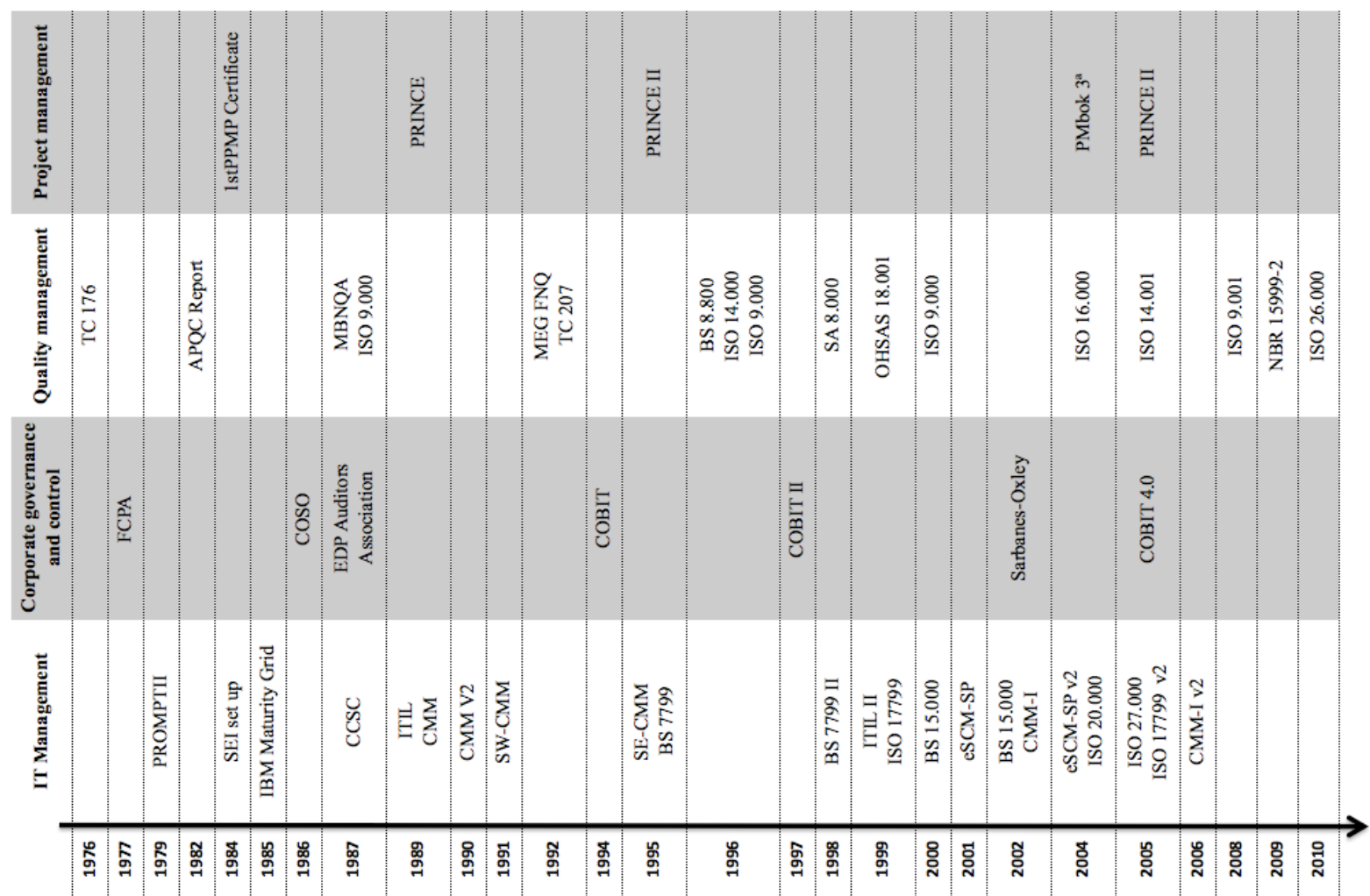

Figure 2. Reference model timeline. Source: PAGLIUSO et al. (2010)

BERNARDO et al. (2008) explain that the standards most commonly implemented among the reference models defined are those proposed by ISO, viz.: ISO 9001:2000 for Quality Management Systems (QMS) and ISO 14001:2004 for Environmental Management Systems (EMS). According to ISO figures, by 2007, more than 897,000 companies worldwide were ISO 9001 certified and more than 129,000 organizations were ISO 14001 certified (ISO, 2007). These numbers reflect the importance of the ISO 9000 standards as the model most adopted in the world and as the major disseminator of the importance and applicability of other references. BERNARDO et al. (2008) explains that EMSs have often been applied, in parallel or sequentially, in organizations that already use some other reference model.

The Malcolm Baldrige National Quality Award (MBNQA) is another important management reference model. FORD \& EVANS (2000) state that MBNQA has become a mechanism to help organizations improve their competitiveness through constant search in increasing value for customers, improving performance and overall organizational capacity. The MBNQA and other similar awards established by other nations now number more than 75 national and international prizes for management excellence, involving more than 100 countries (GLOBAL EXCELLENCE MODEL, 2004).

The increasing "supply" of models by certification bodies, functions and governments, together with organizations' need to secure legitimacy in the entrepreneurial fabric, has led to a proliferation of references within organizations (JORGENSEN, 2006).

HARRISON \& SHIRON (1999) point out that the use of multiple reference models can represent substantial advantages in the study of organizational management. The first benefit 
they identify is that each reference model brings a different conceptual orientation to bear in viewing organizational problems and their possible solutions. The second benefit is managers' increased ability to judge each of the reference models adopted, and the possibility of evolving them. Lastly, multiple reference models applied to an organization lead to different paradigms and prospects of results, producing more complex understandings of management, which makes for better organizational fit and systemic vision.

Also, using more than one management reference model in decision-making can endow greater clarity about the assumptions embodied in the organization's members' mental models, and can help to break down assumptions made when a specific reference adopted is inappropriate to the situation of the organization in question (HARRISON \& SHIRON, 1999).

Although reference models are designed to support organization management, it has to be understood that they differ in focus and emphasis. Some are more abstract than others; some consider the organization as a whole, while others focus on specific sectors. VOM BROCKE (2007) warns that this multiple use can result in greater complexity in managing the management project, organizational diagnosis and learning.

In practice, combining a large number of management references can lead to an excessively fragmented approach, difficult to grasp and analyze. PIDD (2004) explains that complexity partly reflects peoples' inherent cognitive limitations. (NORUZI \& RAHIMI, 2010) add that, regardless of their type of intelligence, professionals generally find it difficult to work with more than four or five management reference models. As noted by DE GUESS (1988), “most people can deal with only three of four variables at a time, and do so through only one or two time iterations”. Similarly, LARICHEV \& MOSKOVITCH (1985) suggest that decision makers only grasp completely those problems where there are at most 5 to 8 structural units interacting in the representation.

\section{One possible approach: an integrated organization reference model}

In view of how difficult it is for organizations to use a diversity of references, this section proposes to present, as one possible approach, the development of an organization reference model; that is, the model resulting from selecting, evaluating and integrating references to be adopted by a particular organization. The logic interconnecting the organization's management practices must be explicitly formulated, so as to enable decision-making to proceed in alignment with a specific, explicitly-stated logic. In other words, there must be a model representing the specific interconnections among the practices of the organization in question.

Consistent with this view, TAYLOR (2001) argues that the use of models and tools favors the establishment of an overall vision. That overall vision, in turn, can be used to encourage and promote leadership behavior. Adopting a model to guide management, he argues, favors: (1) creation of a common vision; (2) establishment of vocabulary and language to be known and understood by every one; and (3) identification of implementation success criteria. These advantages can be regarded as capable of aligning the principles and values chosen for 
management with organizational culture, underpinning the organization's guiding conceptual framework and its members' development by promoting understanding in homogeneous language. Such an approach is particularly significant in organizations with dispersed powers (MAINARDES et al., 2011).

\subsection{The uniqueness of each organization's reference model}

One of the main issues considered in the literature is that a model is a generic representation, which should serve only as a point of departure for developing a specific solution customized to the context where the organization is embedded. For that to happen, the organization must adapt the reference model to its own realities (BECKER et al., 2007).

The results of SEBASTIANELLI \& TAMINI (2003) indicate that, in spite of the advances represented by reference models, use of such models alone does not overcome the obstacles to company management. There is a conflict between theoretical guidance for firms and the real situations where practical solutions have to be implemented, resulting from the specifics of their culture, composition of the labor force, and work processes.

The conclusions of BOYER \& FREYSSENET (1995), regarding the paradox between uniqueness and plurality of models, state that no reference model has been reproduced identically, and that a model is certainly not a stable, closed system that develops only as a result of external constraints.

Accordingly, this section emphasizes that, in order to format a management reference model, an organization can opt to use a set of reference models, but not in disregard of established culture. SCHEIN (1997) describes organizational culture as a pattern of sharing of basic presuppositions, which the group learns as it solves problems of external adaptation and internal integration, and which is sufficiently well worked through to be valued - and, accordingly, to be taught to new members - as the right way to perceive, think and feel in relation to those problems.

In this respect, an organization's reference model will embody the combination of the various models' orientations regarding the peculiarities and characteristics that are exclusive to that specific organization - and it is that combination that makes each reference model unique, even when the organizations start with the same references.

\subsection{Constructing a reference model from multiple references}

FETTKE \& LOOS (2007) present a framework that organizes the process of formulating reference models into two stages: (1) the construction process, which is the first stage of reference modeling and results in a generic model; and (2) the application process, which is the utilization of this model by an organization, which results finally in its adaptation to that organization's specific situation. The goal of the construction process is to design and build a specific reference model. Its main activities are definition of the problem, and the development, evaluation, and subsequent maintenance of the model. SCHUETTE \& ROTTHOWE (1998) note that this process can be considered a non-deterministic process, because different designs can produce different reference models of the same firm. 
The process of applying the reference model is divided into: selecting the reference model, adapting the model to the organization, using it, and integrating it into the organization. The main goal is given by the notion of the organization's re-utilizing the information and knowledge base contained in the model for the purpose of structuring its policies, practices and processes in such a way as to achieve best performance.

They point out that these processes are separate in time, and are usually conducted by different teams, in view of their divergent goals. The key object of interest to this article is in the move from a set of models constructed in processes analogous to cycle 1, and which will be made consistent in the application dimension (cycle 2) of a particular organization.

The location of this object in the framework of FETTKE \& LOOS (2007) highlights an issue that is unresolved in the literature, which largely examines the process of applying a generic reference model to contemplate the particularities of a specific organization, but does not consider introducing the set of models collectively into an organization. That discussion of the multiple orientations that are offered to organizations, and the concern with their consistency and sufficiency, is addressed from another angle in the Operations Strategy field, in the concept of "fit", of how well-adjusted the elements of the organization are to one another (HAYES et al., 2008; ROBERTS, 2005).

The sections below address issues relating to the process of designing an organization reference model, from identifying the references that are to be applied, adapting them to the realities of the organization, through to their joint application and the related integration strategy.

\section{Selection: defining the reference models to be adopted}

First of all, there are the references adopted, which are the key starting point for constructing the organization reference model, because they give the set of requirements and guidelines on which the organization's practices will be built. In other words, the reference models will indicate, in greater or lesser detail, how organizations are to be managed, by stipulating what requirements have to be met, or how that is to be done; they interrelate the main organizational issues, supporting the decision makers with an explicitly-stated logic.

KUJALA \& LILLRANK (2004) explain that an organization can select its management practices from within a vast pre-existing set of solutions that are "supplied" through multiple channels, and which offer different opportunities for gains. Despite the variety of existing reference models, few studies in the literature are directed to verifying and documenting current reference models (THOMAS, 2007). As a result, there is also a lack of studies of which reference models should be used in which situations (OUYANG et al., 2010).

Very few approaches tackle the systematization of reference models (THOMAS, 2005). The most comprehensive results were achieved by the analyses of FETTKE \& LOOS (2005) of a catalog based on reutilization of information reference models, where they transferred the construction catalog concept used in engineering to systems reference modeling. In such a scenario of multiple models and lack of sources for a structured search for references to be adopted, one possible approach consists in a prior endeavor to determine what subjects are 
important to the business and, on that basis, orient the selection of models.

\subsection{Management themes: defining the subjects relevant to the organization}

What is proposed in order to select the references is a prior activity: definition of the themes that will govern the reference model for the organization in question. Even though these may be revised later, they are important initially to orienting the reference models to be considered. The role that open-frame and supply chain models of organizations can play at this stage in defining management themes are set out below.

Definition of the management themes applicable to the organization can start with "universal", open, non-prescriptive reference models, such as the MBNQA, and frameworks, such as the PDCA, which seem to possess a high integrative potential. SEGHEZZI (1997) highlights some advantages of using these models as a foundation structure: (1) they are widely used by organizations; (2) universities are increasingly involved in studying them; (3) they have strong supporters, such as the JUSE (Japanese Union of Scientists and Engineers), EFQM (European Foundation for Quality Management) etc.; (4) there are self-evaluation tools available for them; and (5) there are prizes associated with them, promoting their application.

Following an analogous line of argument, BURLTON (2010) presents, as an example of a generic model in his typology, the Process Classification Framework (PCF) of the American Productivity and Quality Center (APQC) (APQC 2009). He regards the PCF as a useful reference in that "it is comprehensive, covering not only core processes but also, enabling, guiding, and managing the ones that some other frameworks overlook”.

Two other models that should be mentioned are generic process structures at their most aggregate levels, which are presented as universal even though they are suggested for organizations for which their position in the supply chain is a characteristic trait. The first of these is the Supply Chain Operations Reference (SCOR), which takes the process perspective and seeks to cover all the activities in a chain of connected processes from the supplier's supplier to the customer's customer, inside and outside the firms (SCC, 2009). The second is the Value Reference Model (VRM), which takes a broader approach than the SCOR by including the product development and customer relations perspectives (VALUE CHAIN GROUP, 2009).

Depending on the industry of the organization for which the reference model is being constructed, there is also the possibility of building on industry-specific models. There are a series of theoretical models focused on specific types of organization, which highlight significant themes for the business in question. BURLTON (2010) explains that the assumption implicit in these models is that, at the basic level, each "player" in the industry is essentially the same as all the others. One example of this type of model is the e-TOM (TMFORUM, 2009) which describes a generic telecommunications organization.

Another example of a model that brings in business-specific features is the Governments Strategic Reference Model (GSRM) developed by the government of Canada. This is an interesting example in that it takes the lifecycle perspective of a generic government service; 
its patterns are designed to be used by governments to manage the life of services at each of the stages of maturity (TREASURY BOARD OF CANADA SECRETARIAT, 2009). Note here that the organization format in the reference model - i.e., whether it is to be structured by processes, by functions, by life cycle etc. - is guided by the characteristics of the business in question; and also that the basic reference model itself can shape that decision.

The fact that they furnish a holistic view of the organization enables them to "absorb" other reference models in a more structured fashion. When the criteria and items proposed by these types of model are analyzed in the light of the culture of the organization in question, this results in identification of themes that should be more or less strongly emphasized. This is a creative activity, strongly based on tacit knowledge, which tends to yield better results when it involves more personnel who understand the organization thoroughly.

The organization's value chain or process map, whether constructed on the basis of references like APQC, SCOR and VRM or not, are also possible sources of insights, because they tend to make important aspects of the business explicit. However, care must be taken with representations that carry with them the strong influence of the organization chart. Management themes that reflect the functional structure tend to turn into disjointed models, where solutions are thought about strictly within the boundaries of each area, without ensuring the overall vision.

If these foundations are available as a point of departure for constructing the model - whether they are open or value chain models - they will facilitate and expedite definition of the themes. Their absence, however, does not prevent definition of the management themes. In the latter situation, defining them depends on a creative effort by the organization's managers and/or staff.

\subsection{Issues associated with selection of reference models for the defined themes}

Once the management themes have been established, the next stage is to select the specific models and norms for each theme; at this stage the organization has to choose the initial set of references that it is to consider. THOMAS (2005) reports that studies in the reference modeling field must often deal with the fundamental problem of finding and locating reference models. These references can be informative for the organization as a whole or restricted to specific aspects. Selection of models is a crucial task, which demands a good understanding of the reference models available in various domains (OUYANG et al., 2010).

Here the scope of selection must go beyond the sample of institutionally supported reference models. THOMAS (2005) argues that it is relevant to the user of a model whether the model whose content he wants has been declared a reference model or not. Their decision to use a reference model will be guided solely by whether or not they recognizes a potential benefit in the model. For example, for the theme "Operations Management", the Lean Production Model or the Toyota Production System could be taken as reference models. In this regard, it is very important also to contemplate the related conceptual frameworks.

THOMAS (2005) argues that when a model is located, the organization must decide whether or not it is a reference model. The organization seeking models faces a problem in taking this 
decision. After all, he explains, you can only decide subjectively if a model is a relevant reference model. To this problem is added the fact that, even though some individuals may accept a model as a reference, that does not mean that others will also do so.

The choice of an appropriate reference model must consider issues such as availability, domain of application, potentials and limitations (FETTKE et al., 2005). In addition, the choice of models must weigh the benefits that models with different views bring to the analysis of the problem against the difficulty of managing them. FETTKE et al. also warn that some organizations may be frustrated at encountering widely differing models. Another point to be considered is the added value and the recognition that a new model will bring. Each model deployed should contribute in a way that the others are unable to (BERNARDO et al., 2008).

HARRISON \& SHIROM (1999) offer some ideas to guide this selection process. It should be ascertained that the model is able to provide useful and effective return on organizational problems and future challenges. Prominent here are the organization's strategic issues, and the reference's contribution to sustainable performance and to the ethical model (TAKEI, 2011). Another important aspect of the choice is the ability to separate symptoms from root-causes. This quality enables users to act on the causes of problems, rather than on their consequences or symptoms. Another allied quality that the choice of reference models should look for is the ability to help managers chart organizational learning pathways. Directly or indirectly, these references are used to guide operational diagnosis and learning. Lastly, one of the most interesting and complex aspects of choosing reference models is the association between their characteristics and the organization's goals and values.

\section{Adapting models for joint use and to the realities of the organization}

VOM BROCKE \& THOMAS (2006) argue that one of the most important issues when conceiving a reference model is what makes the reference model created a marketable product. Aside from quality issues, which have been dealt with in the previous section, the user of reference models is going to be guided, above all, by the effort needed to adapt them. A user will recognize the usefulness of a reference model when the effort needed to construct his specific model is considerably reduced by using that given reference model.

The effort needed to adapt the reference model to a firm's specific situation is small when many of the specific features of its industry are represented by the model. However, the more specific a reference model, the fewer firms it will be applicable to; that is, potential demand for the model will be smaller. Greater demand for a reference is only made possible by increasing the number of classes of businesses or use-cases it applies to. That, however, results in an increase in the effort required of the perspective user to adapt the reference model, which in turn reduces the model's usefulness to the user (VOM BROCKE \& THOMAS, 2006).

Although the problem described above, which BECKER et al. (2002: 26) call the "dilemma of reference modeling”, is an abstract argument, it does make it clear that model developers face elementary problems in identifying a market for their products. In view of that scenario, 
the topics below consider how organizations deal with the models that position themselves in different ways on the market.

\subsection{The consistency of the reference models selected}

Reference models are generally collective products and are linked to corporate outlooks. In the medium and long terms, these outlooks mean that the models become competing products on specific markets. As a result, corporations - sets of professionals with market interests tend to be uninterested in facilitating integration of "their" model with the others. There is a tendency for these corporations to defend their products to the detriment of the others.

Consider, for example, the hypothesis of models directed to theme $\mathrm{X}$. Why should corporation $\mathrm{AB}$ bother to indicate the point of connection with the model proposed by corporation CD? Even though the objects addressed in theme $\mathrm{X}$ are complementary, the bodies that promote them take the position that their model contains everything necessary for good management of $\mathrm{X}$ and, accordingly, there is no reason to be interested in other models.

However, even though some groups do nothing to facilitate the work of inter-relating their orientations, that work tends to be made easier when the objects of analysis are reduced to management themes. This is because the greater the degree of detail (the more you go into the requirements and orientations), the more evident the similarities and divergences between the proposed solutions become. This reduction of the object is one of the "rules of thumb" or heuristics offered by BROCKMAN (2010) in the expression "divide and conquer”.

Information Technology, for example, is one domain with widely-marketed models (BURLTON, 2010), among the most recognized of which is ITIL (IT GOVERNANCE INSTITUTE, 2009), a model of best practices that support IT service management. ITIL is particularly strong in support areas, but weak in aspects of overall IT management, for which it can be completed by other models. One good "partner model" is COBIT, which was originally developed as an IT auditing structure by the nonprofit organization, ISACA, but is being recognized more for overall IT management (IT GOVERNANCE INSTITUTE, 2009).

When working with multiple preference models, some contradictions can be resolved by logical analysis or even through empirical studies. One option in order to create a dialog is to try to set out the main points or components on which the models diverge. Once these dimensions are identified, it may be possible to find zones where they overlap (HARRISON \& SHIROM, 1999). Another option proposed by the same authors is to bridge between the models at the level of requirements or practices. That approach rests on pragmatic movements that combine elements of different models and foster ways of overcoming the conflicts between them.

HARRISON \& SHIRON (1999) point out that apparent conflicts between reference models can produce complementary perspectives if they are analyzed at different levels. They thus suggest that modeling the organization at the macro and micro levels can yield a better vision of the organizational characteristics and more reliability in the macro-orientation. This strategy connects with another work heuristic that BROCKMAN (2010) describes as "working top-down and bottom-up". 
In order to adjust different reference models successfully it is necessary to observe the degree of complementarity of opposition between them, and to specify the elements that create that complementation or opposition, and where possible, paths for dealing with the divergences (HARRISON \& SHIRON, 1999). From the point of view of the organization that is setting up its model by building on various reference models, issues of integration among the latter are critical. In some cases, that integration has to be discussed in connection with each relevant activity on the organization process map. That method is lengthy, and entails allocating professionals from various specialties in the organization. Discussion, activity by activity of the process map and guided by a structured set of policies (both for within the organization, and between it and its surroundings), is one alternative that can bring consistency to the organization reference model.

\subsection{Means of integrating the selected references}

When an organization opts to undertake integration of its multiple references, this can occur in numerous ways. Some authors have identified and categorized some forms of integration. Table 1 below consolidates these positions.

Table 1. Forms of integration

\begin{tabular}{|l|l|}
\hline \multicolumn{1}{|c|}{ Authors } & \multicolumn{1}{c|}{ Forms of integration } \\
\hline $\begin{array}{l}\text { Seghezzi } \\
\text { (1997) }\end{array}$ & $\begin{array}{l}\text { Addition, where cross-referenced lists are drawn up so as to make the } \\
\text { models comparable; merger, where the organization uses one of the } \\
\text { models to orient the construction of its own model; and integration, } \\
\text { where the organization opts to choose or develop one particular model } \\
\text { and integrate the others models adopted into it. }\end{array}$ \\
\hline \multirow{2}{*}{$\begin{array}{l}\text { Wilkinson } \\
\text { Dale (1999) }\end{array}$} & $\begin{array}{l}\text { The first involves introducing models across all the organization's } \\
\text { functions and activities; the second is combining models on the basis of } \\
\text { whatever structural similarities are identified; the third is integrating the } \\
\text { organization's main models with extremely specific models regarded as } \\
\text { totally covering a given part of the organization; and the last is } \\
\text { constructing a single model aligned with the policies and goals of each } \\
\text { original model, and supporting the organizational policy. }\end{array}$ \\
\hline Kirkby (2002) & $\begin{array}{l}\text { Separate, where each model is introduced in a different area (or selected } \\
\text { elements of that model are); aligned, where the main elements of the } \\
\text { models are aligned, but the models remain separate; and integrated, } \\
\text { where a single model is created. }\end{array}$ \\
\hline (2002) & $\begin{array}{l}\text { Integrating documentation, which consists in creating a common manual } \\
\text { which serves all the specific models, and may or may not go as far as the } \\
\text { creation of single manuals for the procedures; aligning the main } \\
\text { processes, goals and resources for managing the models; and }\end{array}$ \\
\hline
\end{tabular}




\begin{tabular}{|l|l|}
\hline & “all-in-one”, which is a universal model encompassing all the others. \\
\hline $\begin{array}{l}\text { Karapetrovic } \\
\text { (2003) }\end{array}$ & $\begin{array}{l}\text { Partial integration, which may be no more than simple collaboration, but } \\
\text { can go as far as alignment of models' goals, processes and resources; and } \\
\text { complete integration, where the original models loose their identities to } \\
\text { form one single integrated model. }\end{array}$ \\
\hline $\begin{array}{l}\text { Beckmerhagen } \\
\text { et. al. (2003), }\end{array}$ & $\begin{array}{l}\text { Harmonization, which involves identifying the relationships among the } \\
\text { requirements for practices of various models, as well as adopting a } \\
\text { main elements according to a specific framework; and amalgamation, } \\
\text { which means integrating specific elements by forming a single entity } \\
\text { with modules for each function. }\end{array}$ \\
\hline Pojasek (2006) & $\begin{array}{l}\text { Combined, where the models are implemented at the same time within } \\
\text { the organization; integratable, where the models' common elements have } \\
\text { been identified; integrating, where these common elements identified are } \\
\text { being integrated; and integrated, where there is one model incorporating } \\
\text { all these common elements of the other models. }\end{array}$ \\
\hline $\begin{array}{l}\text { Jorgensen } \\
\text { (2008) }\end{array}$ & $\begin{array}{l}\text { Correspondence, which is cross-referencing and internal coordination of } \\
\text { the different models; generic, which is the integration of generic points of } \\
\text { the models; and integration, which is the creation of a culture of learning } \\
\text { with stakeholder participation. }\end{array}$ \\
\hline
\end{tabular}

Source: constructed from FONTES (2010)

From Table 1 it can be seen that the forms of integration found in the literature are often very similar. Detailed analysis reveals that there are even some equivalences, although that is not true for all of them. By a analyzing their characteristics, FONTES (2010) arrived at a proposition of 4 forms of integration with different characteristics, which summarize the studies found in the literature, viz.:

1. Separate reference models: in this situation the models are adopted as the organization's needs arise, and are implemented in the areas they support. Accordingly, each area manages the models as best suits its interests, and there is no concern to discover whether there are similarities that could be used for better organization of efforts associated with following their guidance. Organizations in this situation are characterized by not having embarked on a process of integration of the references. Most authors regard this method as having the immediate disadvantage of multiplying the organization's efforts to manage the models (ZENG et al., 2007).

2. Aligned reference models: the chief characteristic of this kind of integration is that it seeks alignment among the reference models adopted by the organization. This alignment is achieved by identifying the common elements existing among these models, from which it is 
possible to distinguish redundancies and synergies among those elements (KARAPETROVIC, 2003). There is the risk of this process been reduced to simply merging documentations, and ignoring aspects such as policies and cultural changes (WILKINSON \& DALE, 1999).

3. Articulated reference models: the starting point For this situation is similar to the previous one, however, with some additional fundamental characteristics, viz.: (1) selection of a model or some other conceptual structure able to guide the inter-relations of the other reference models (KARAPETROVIC, 2003); and (2) once the similar elements have been identified and inter-related, it is possible to develop a unified documentation encompassing all the models. With this documentation in hand, it is intended that the various areas of the organization will use the model more consciously, given that they have a single document to guide them.

4. Integrated reference models: here, after identifying and aligning the common elements, the organization analyzes each of the groups of elements, and fits them to its realities. On the basis of that analysis, it re-formulates suitable elements that comply with the original models and also configure its own model.

As can be seen, there is a kind of maturation as one progresses through these forms of integration. However, organizations need not necessarily have gone through all the previous forms in order to fall within any given format.

\subsection{The possible introduction strategies}

BERNARDO et al. (2008) discuss the effort of integrating and fitting reference models to the realities of a particular organization. These authors consider implementation strategy to be a decision as to which reference models the organization is going to integrate and in what order. The proposition most found and accepted in the literature is the one formulated by KARAPETROVIC \& WILLBORN (1998) which proposes integration based on two main types of reference model, quality management systems (QMSs) and environmental management systems (EMSs).

The proposal by KARAPETROVIC \& WILLBORN (1998) comprises two stages. At the first, there are three options: (1) first integrate the QMSs and then the EMSs; (2) integrate the EMSs and then the QMSs; and (3) integrate QMSs and EMSs simultaneously.

KARAPETROVIC \& JONKER (2003) subsequently proposed an integration strategy for when firms adopt many types of model (that is, beyond QMS and EMS). On the basis of the first option, i.e., integrating the QMS and then the EMS, the authors suggest the following sequence: (1) integrate the QMS and other MSs that are based on the process approach; (2) integrate the EMS and then the other references based on the PDCA model; and (3) link up these function- or domain-specific models; align them or make them compatible, and integrate them.

\section{Final remarks}

To sum up, this article sought to highlight a real problem facing many organizations today: 
their need to structure the deployment of multiple references available on the market and in academia. It began by delimiting the object in question on the basis of definitions of what is understood by "reference model", and then listed the various types in existence and their intrinsic characteristics. The article then sought to develop the conceptual structure surrounding the role of reference models in an organization's development, and to discuss the impacts resulting from their increasing adoption. It then followed by proposing the establishment of a specific integrated model for an organization as a way of dealing with the multiple reference models available to them.

The desired result was a single organization model that contemplated characteristic traits of the organization's culture and business. No methods were found in the literature to guide the work of formulating such a model. The method of FETTKE \& LOSS (2007) was presented, because it displays many similarities with the other methods used for conceiving generic references in the information sciences domain, and for subsequently introducing one of such models into an organization. However, it contemplates neither the process of identifying models relevant to the organization's realities, nor consistency evaluation among the multiple references selected, and between them and the organization.

Figure 3 summarizes the main stages and issues associated with the proposition of this article, which were addressed in the previous sections. That proposal constructs an organization model through an articulated solution based on one or more references that were selected thematically, adjusted for coherence and inter-relationship, examined in the light of the organizational culture, and formulated explicitly.

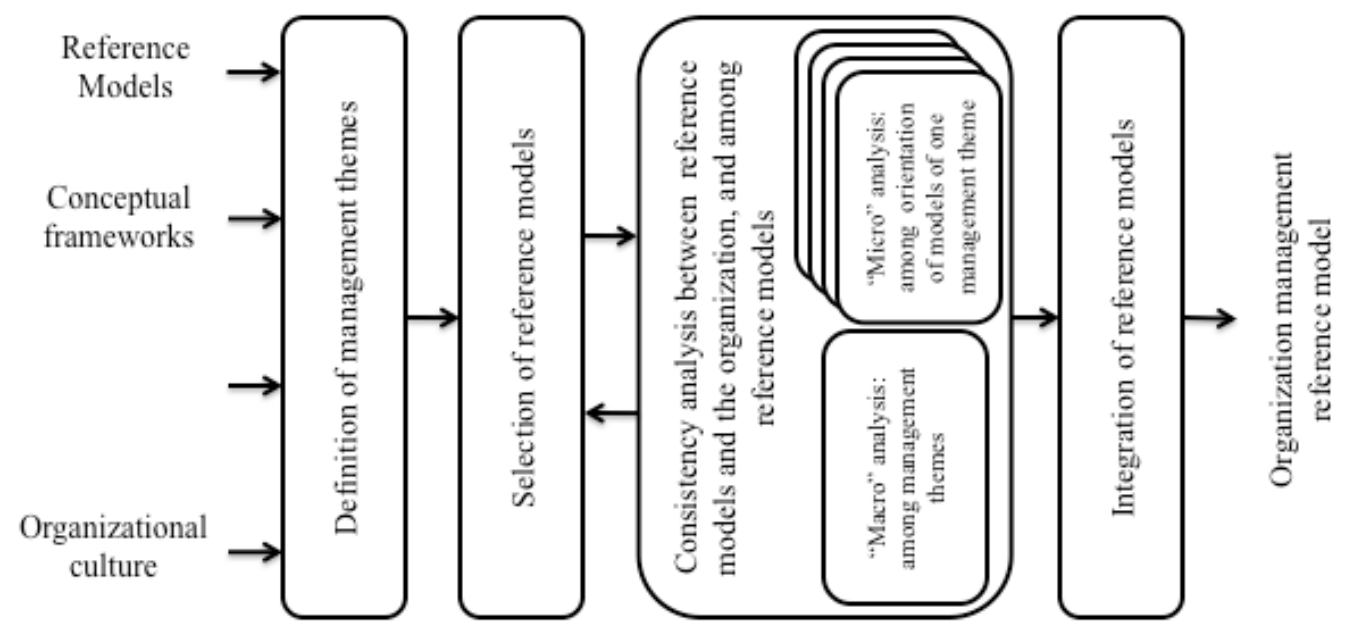

Figure 3. Stages in the construction of the Management Reference Model. Source: the authors.

Here it should be stressed that the issues discussed relate to the conception of a first version of the organization reference model, which tends to be dynamic. This article concludes then, in view of the scenario of an evolving model, by mentioning the that reference model's potential in future stages of its maturation. By the fact that it defines the relationship among the themes, and states them explicitly, it can be more easily able to include new models that may come to be adopted by the organization. As soon as the focus of the new reference is 
identified, it will be easier to define what parts of the integrated reference model it should be "added" to. Also, this model tends to be able to indicate areas of the organization and/or themes of interest to it that are not been covered by any model, and thus a model appropriate to the organization can be selected, if this is considered important.

\section{References}

APQC. (2009). [Online] Available: http://www.apqc.org.

Aslam, H. D., Sarwar, S. (2010). Improving Performance Management Practices in IT Firms of Pakistan, Journal of Management Research, 2, 2: E2.

Becker, J., Delfmann, P., Knackstedt, R. (2007). Adaptive Reference Modeling: integrating configurative and generic adaptation techniques for information models. In: Becker, J., Delfmann, P. (eds). Reference Modeling: efficient information systems design through reuse of information models, New York: Physica-Verlag Heidelberg, 27-58.

Beckmerhagen, I., Berg, H., Karapetrovic, S., Willborn, W. (2003). Integration of management systems: focus on safety in the nuclear industry, International Journal of Quality and Reliability Management, 20, 2, 210-228. http://dx.doi.org/10.1108/02656710310456626

Bernardo, M., Casadesus, M., Karapetrovic, S., Heras, I. (2009). How integrated are environmental, quality and other standardized management systems? An empirical study. $\begin{array}{llllll}\text { Journal of Cleaner } & \text { Production, } & 17, & 8, & 742-750 .\end{array}$ http://dx.doi.org/10.1016/j.jclepro.2008.11.003

Boyer, R., Freyssenet, M. (1995). Emergence of new industrial models: hypothesis and analytical procedure. Actes du GERPISA, 15.

Brockman, J. (2010). Introdução à Engenharia: modelagem e solução de problemas. LTC.

Burlton, R. (2010). Delivering Business Strategy Through Process Management. In: Vom Brocke, J., Rosemann, M. (eds), Handbook on Business Process Management, Springer, 2, 5-37.

De Guess, A. (1988). Planning as learning, Harvard Business Review, March/April, 74.

Fettke, P., Loos, P. (2007). Perspectives on Reference Modeling”. In: Fettke, P., Loos, P. (eds) Reference Modeling for Business Systems Analysis. Idea Group Publishing, Hershey, 1- 2.

Fettke, P., Loos, P., Zwicker, J. (2005). Business Reference Model: Survey and Classification. $3^{\circ}$ International Conference on BPM, France.

Fontes, M. T. (2010). Um Instrumento para Pesquisar a Integração de Múltiplos Modelos de Referência nas empresas brasileiras. M.Sc. Thesis, COPPE/UFRJ, Rio de Janeiro, RJ, Brazil.

Ford, M. W., Evans, J. R. (2000). Conceptual foundations of strategic planning in the Malcolm Baldrige criteria for performance excellence. Quality Management Journal, ASQ, 7, $1,8-26$. 
Harrison, M. I., Shirom, A. (1999). Organizational Diagnosis and Assessment. California: Sage Publications.

Hayes, R., Pisano, G., Upton, D., Wheelwright, S. (2008). Produção, estratégia e tecnologia: em busca da vantagem competitiva. Porto Alegre: Bookman.

Information Systems Audit and Control Association (Isaca) [Online] Available: http://www.isaca.org.

ISO. “About ISO”, TC 207. [Online] Available: http://www.tc207.org/About207.asp.

IT Governance Institute, 2009. [Online] Available: http://www.itgi.org.

Jorgensen, T. (2008). Towards more sustainable management systems: through life cycle management and integration. Journal of Cleaner Production, 16, 10, 1071-1080. http://dx.doi.org/10.1016/j.jclepro.2007.06.006

Karapetrovic, S. (2003). Musings on integrated management systems. Measuring Business Excellence, 7, 1, 4-13. http://dx.doi.org/10.1108/13683040310466681

Karapetrovic, S. (2002). Strategies for the integration of management systems and standards. The TQM Magazine, 14, 1, 61-67. http://dx.doi.org/10.1108/09544780210414254

Karapetrovic, S., Jonker, J. (2003). Integration of Standardized Management Systems: Searching for a Recipe and Ingredients. Total Quality Management, 14, 4, 451-459. http://dx.doi.org/10.1080/1478336032000047264

Karapetrovic, S., Willborn, W. (1998). Integration of quality and environmental management systems. The TQM Magazine, 10, 3, 204-213. http://dx.doi.org/10.1108/09544789810214800

Keller, G., Teufel, T. (1998). SAP R/3 process-oriented implementation. England: Harlow, Addison Weley Longman.

Kirkby, A. (2002). The one-stop shop. Qualityworld, integrated management, IQA, 2-4.

Kujala J., Lillrank, P. (2004). Total Quality Management as a Cultural Phenomenon. Quality Management Journal, Milwaukee, USA, ASQ, 11, 4, 43-55.

Larichev, O. I., Moskovitch H. (1985). Limits to Human Decision Makers’ Effectiveness. In: Brehmer, B., Jungermann, H. Lourens, P., Sevon, G. (eds), New Directions in Research on Decision Making. North Holland, Amsterdam.

Limsarun, T., Anurit, P. (2011). The Different Perspective of Managerial and Operational Level toward Customer Relationship Management Practice in Thailand, Journal of Management Research, 3, 1: E2.

Mainardes, E. W., Raposo, M., Alves, H. (2011). Organizations with Dispersed Powers: Suggestion of a New Management Model Based on the Stakeholders Theory, Journal of Management Research, 3, 1: E7.

Malcolm Baldrige National Quality Award (2009). Criteria for performance excellence 
2009-2010. USA.

Matook, S., Indulsk, M. (2009). Improving the Quality of Process Reference Models: a quality function deployment-based approach, Decision Support Systems, 47, 1, 60-71. http://dx.doi.org/10.1016/j.dss.2008.12.006

Noruzi, M. R., Rahimi, G. R. (2010). Multiple Intelligences, A New Look to Organizational Effectiveness, Journal of Management Research, 2, 2: E4.

Ouyang, C., Adams, M., Wynn, M.T., TER Hofstede, A.H.M. (2010). Workflow management. In: Vom Brocke, J., Rosemann, M. (eds), Handbook on Business Process Management, Springer, 1, 387-418.

Pagliuso, A. T., Cardoso, R., Spiegel, T. (2010). Gestão organizacional: o desafio da construção do modelo de gestão, São Paulo: Instituto Chiavenato (org.), Saraiva.

Pidd, M. (1999). Just Modeling Through: A Rough Guide to Modeling, Lancaster University.

Pidd, M. (2004). Systems Modelling: Theory and Practice. Wiley.

PMBOK®, 2009. [Online] Available: http://www.pmi.org.

Pojasek, R. (2006). Is your integrated management system really integrated?, Environmental Quality Management, 16, 2, 89-97. http://dx.doi.org/10.1002/tqem.20124

Recker, J., Rosermann, M., Van Der Aalst, W. M. P., Jansen-Vullers, M., Dreiling, A. (2007). Configurable reference modeling languages. In: Fettke, P., Loos, P. (eds), Reference modeling for business systems analysis, Hershey: Idea Group Publishing.

Roberts, J. (2005). Teoria das organizações: redesenho organizacional para o crescimento e desempenho máximos. Rio de Janeiro: Elsevier.

Rosemann, M., Van Der Aalst, W. M. P. (2007). A Configurable Reference Modelling Language. Information Systems, 32, 1-23. http://dx.doi.org/10.1016/j.is.2005.05.003

Schein, E. (1997). Organizational culture and leadership. San Francisco: Jossey-Bass.

Schelp, J., Winter, R. (2006). Method Engineering: lessons learned from reference modeling. Design Science Research, Information Systems and Technology, Claremont (USA), 24-25 Feb.

Schütte, R., Rotthowe, T. (1998). The Guidelines of Modelling: an approach to enhance the quality of information models, Conceptual Modeling - Lecture Notes in Computer Science, Berlin: Springer-Verlag, 1507, 240-254.

Sebastianelli, R., Tamini, N. (2003). Understanding the Obstacles to TQM Success, Quality Management Journal, Milwaukee, USA, ASQ, 10, 3, 45-56.

Seghezzi, H. (1997). Business concept redesign, Total Quality Management, 8, 2/3, 36-43. http://dx.doi.org/10.1080/0954412979677

Software Engineering Institute. (2005). CMMI. Carnegie Mellon University. 
Shehabuddeen, N., Probert, D.; Phaal, R., Platts, K. (1999). Representing and approaching complex management issues: Part 1 - Role and definition, Centre for Technology Management Working Paper Series, USA, University of Cambridge Institute for Manufacturing.

Supply Chain Council. (2009). [Online] Available: www.supply-chain.org.

Takei, H. (2011). Strategic Frameworks of Ethic Management in MNEs: Theoretical Discussions and Model Development, Journal of Management Research, 3, 2: E1.

Taylor, L. J. (2001). Selecting and Implementing Quality Management Models, Annual Quality Congress, Charlotte, NC, 55, 286-291.

TMForum. (2009). [Online] Available: www.tmforum.org.

Treasury Board of Canada Secretariat. (2009). [Online] Available: www.tbs-sct.gc.ca/btep-pto/documents/2004/pat terns-patrons/patterns-patrons00-eng.asp.

Value Chain Group (2009). [Online] Available: www.value-chain.org/.

Thomas, O. (2005). Understanding the Term Reference Model in Information Systems Research: History, Literature Analysis and Explanation. Proceedings of the $3^{\text {rd }}$ International Conference on Business Process Management (BPM), 16-29.

Thomas, O. (2007). Reference Model Management. In: Fettke, P., Loos, P. (ed), Reference Modeling for Business Systems Analysis, Idea Group Publishing. Hershey. 288-209. http://dx.doi.org/10.1007/978-3-7908-1966-3_1

Union of Japanese Scientists and Engineers (JUSE). [Online] Available: http://www.juse.or.jp/e/index.html.

Van Der Aalst, W. M. P., et al. (2005). Configurable Process Models as a Basis for Reference Modeling, Proceedings of the 3rd International Conference on Business Process Management (BPM), 1-15.

Vernadat, F. B. (1996). Enterprise Modeling and Integration: principles and applications. London: Chapman \& Hall.

Vom Brocke, J., Thomas, O. (2006). Reference Modeling for Organizational Change: Applying Collaborative Techniques for Business Engineering. Proceedings of the Twelfth Americas Conference on Information Systems, Acapulco, Mexico August 04th-06th, 680-688.

Vom Brocke, J. (2007). Design Principles for Reference Modeling. In: Becker, J., Delfmann, P. (eds). Reference Modeling: efficient information systems design through reuse of information models, New York: Physica-Verlag Heidelberg, 58-75.

Wilkinson, G., Dale, B. (1999). Integration of quality, environment and health and safety management systems: an examination of key issues, Proceedings of the Institution of Mechanical Engineers, Part B, Journal of Engineering Manufacture, 213, 3, 275-283. http://dx.doi.org/10.1243/0954405991516750 


\section{Copyright Disclaimer}

Copyright reserved by the author(s).

This is an open-access article distributed under the terms and conditions of the Creative Commons Attribution license (http://creativecommons.org/licenses/by/3.0/). 